\title{
Understanding and tuning blue-to-near-infrared photon cutting by the $\mathrm{Tm}^{3+} / \mathrm{Yb}^{3+}$ couple
}

\author{
Dechao Yu', Ting Yu ${ }^{1,2}$, Arnoldus J. van Bunningen', Qinyuan Zhang ${ }^{2}$, Andries Meijerink (D) and Freddy T. Rabouw (D)
}

\begin{abstract}
Lanthanide-based photon-cutting phosphors absorb high-energy photons and 'cut' them into multiple smaller excitation quanta. These quanta are subsequently emitted, resulting in photon-conversion efficiencies exceeding unity. The photon-cutting process relies on energy transfer between optically active lanthanide ions doped in the phosphor. However, it is not always easy to determine, let alone predict, which energy-transfer mechanisms are operative in a particular phosphor. This makes the identification and design of new promising photon-cutting phosphors difficult. Here we unravel the possibility of using the $\mathrm{Tm}^{3+} / \mathrm{Yb}^{3+}$ lanthanide couple for photon cutting. We compare the performance of this couple in four different host materials. Cooperative energy transfer from $\mathrm{Tm}^{3+}$ to $\mathrm{Yb}^{3+}$ would enable blue-to-near-infrared conversion with 200\% efficiency. However, we identify phonon-assisted cross-relaxation as the dominant $\mathrm{Tm}^{3+}$-to-Yb ${ }^{3+}$ energy-transfer mechanism in $\mathrm{YBO}_{3}, \mathrm{YAG}_{\text {, and }} \mathrm{Y}_{2} \mathrm{O}_{3}$. In $\mathrm{NaYF}_{4}$, in contrast, the low maximum phonon energy renders phonon-assisted cross-relaxation impossible, making the desired cooperative mechanism the dominant energy-transfer pathway. Our work demonstrates that previous claims of high photon-cutting efficiencies obtained with the $\mathrm{Tm}^{3+} / \mathrm{Yb}^{3+}$ couple must be interpreted with care. Nevertheless, the $\mathrm{Tm}^{3+} \mathrm{Nb}^{3+}$ couple is potentially promising, but the host material - more specifically, its maximum phonon energyhas a critical effect on the energy-transfer mechanisms and thereby on the photon-cutting performance.
\end{abstract}

\section{Introduction}

Lanthanide-based phosphors offer wide possibilities for colour conversion, absorbing one colour of light and emitting another ${ }^{1}$. The conversion process often involves energy transfer between lanthanide dopants ${ }^{2,3}$. Consumer applications, such as lighting and displays, usually rely on colour conversion by conventional 'downshifting' luminescence: the material emits one redshifted (lower-energy) photon for each photon it absorbs. The energy level structures of the lanthanides, however, offer more colourconversion possibilities. Unconventional energy-transfer pathways between lanthanide dopants can be designed,

\footnotetext{
Correspondence: Qinyuan Zhang (qyzhang@scut.edu.cn) or

Freddy T. Rabouw (f.t.rabouw@uu.nl)

${ }^{1}$ Debye Institute for Nanomaterials Science, Utrecht University, Princetonplein

1, 3584 CC Utrecht, The Netherlands

${ }^{2}$ State Key Laboratory of Luminescence Materials and Devices, Institute of

Optical Communication Materials, South China University of Technology,

Guangzhou 510641, China

These authors contributed equally: Dechao Yu, Ting Yu
}

which lead to 'upconversion' luminescence ${ }^{4-6}$ or 'photon cutting ${ }^{7,8}$. Upconversion involves merging of the energy of multiple photons by the phosphor material, i.e., it absorbs two (or more) low-energy photons and emits one higherenergy photon. Photon cutting is the inverse process (therefore also known as 'downconversion'), whereby one higher-energy photon is absorbed and two (or more) lower-energy photons are emitted.

This work explores new strategies to achieve photon cutting by lanthanide-doped phosphors. The process was first proposed as a concept that could drastically increase the efficiency of fluorescent lighting, offering the prospect of ultraviolet-to-visible conversion efficiencies of up to $200 \%{ }^{7}$. However, with the advances in blue light-emitting diodes over the past two decades ${ }^{9}$, the societal need for new fluorescent-lighting technologies has decreased. Photon cutting has been identified as a potential method to break the Shockley-Queisser limit of $33.7 \%$ in photovoltaics $^{10-12}$. This limit otherwise sets the maximum 
conversion efficiency of single-junction solar cells under standard solar irradiation, determined by the optimum balance between thermalization losses and transmission losses ${ }^{13}$. A photon-cutting phosphor should reshape the spectrum from the sun before it enters a solar cell by converting high-energy photons into multiple lowerenergy photons. Using this concept, the maximum achievable solar-cell efficiency increases to $\sim 40 \%{ }^{14}$.

Photon-cutting phosphors exhibiting $\mathrm{Yb}^{3+}$ emission have been of particular interest, because the emission at $\sim 10,000 \mathrm{~cm}^{-1}$ matches the bandgap $\left(9000 \mathrm{~cm}^{-1}\right)$ of crystalline silicon solar cells. Desirable phosphors are codoped with a sensitizer ion that absorbs in the visible spectral range and transfers its energy to two $\mathrm{Yb}^{3+}$ ions. Phosphors doped with $\mathrm{Tb}^{3+} / \mathrm{Yb}^{3+}{ }^{8,15}, \mathrm{Ce}^{3+} / \mathrm{Yb}^{3+}{ }^{16-18}$, $\mathrm{Tm}^{3+} / \mathrm{Yb}^{3+}{ }^{19-23}, \operatorname{Pr}^{3+} / \mathrm{Yb}^{3+}{ }^{34,25}$, and other ion couples have been proposed. However, not all types of energytransfer process between ion couples yield two (or more) excited $\mathrm{Yb}^{3+}$ ions per absorption event. For example, the $\mathrm{Ce}^{3+}$-to- $\mathrm{Yb}^{3+}$ energy-transfer mechanism in codoped yttrium aluminium garnet (YAG; $\mathrm{Y}_{3} \mathrm{Al}_{5} \mathrm{O}_{12}$ ) yields only a single $\mathrm{Yb}^{3+}$ excitation, so YAG:Ce $\mathrm{Ce}^{3+}, \mathrm{Yb}^{3+}$ is not a photon cutter despite a favourable energy-level structure ${ }^{16,17}$. Unfortunately, the energy-transfer mechanisms are unclear for many potential photon-cutting phosphors, resulting in contradictory $^{19,20}$ or poorly supported interpretations in the literature ${ }^{12}$. This complicates the identification and optimization of promising photon-cutting materials. Photon correlation measurements are a direct way to prove photon cutting $^{26}$. Unfortunately, these measurements are difficult for $\mathrm{Yb}^{3+}$ emission, because single-photon detectors with high efficiencies and low dark counts are not readily available for the near-infrared region.

Here we study the potential of photon cutting with the $\mathrm{Tm}^{3+} / \mathrm{Yb}^{3+}$ lanthanide couple. The existing literature makes contradictory claims about the mechanism of energy transfer from the $\mathrm{Tm}^{3+}{ }^{1} \mathrm{G}_{4}$ level to $\mathrm{Yb}^{3+12}$, with important implications for the photon-cutting potential of the $\mathrm{Tm}^{3+} / \mathrm{Yb}^{3+}$ couple. A cooperative mechanism would, but a phonon-assisted cross-relaxation mechanism would not, result in blue-to-near-infrared photon cutting with the potential to increase the current output of crystalline Si solar cells ${ }^{10-12}$. We measure and model the dynamics of $\mathrm{Tm}^{3+}$-to- $\mathrm{Yb}^{3+}$ energy transfer in four different host materials with systematically varied doping concentration. We identify phonon-assisted cross-relaxation as the dominant energy-transfer mechanism in $\mathrm{Tm}^{3+} / \mathrm{Yb}^{3+}$-codoped $\mathrm{YBO}_{3}$, YAG, or $\mathrm{Y}_{2} \mathrm{O}_{3}$. In contrast, cooperative energy transfer dominates in $\mathrm{Tm}^{3+} /$ $\mathrm{Yb}^{3+}$-codoped $\mathrm{NaYF}_{4}$. Consequently, only $\mathrm{NaYF}_{4}$ is a promising host material to achieve photon cutting for silicon photovoltaics with the $\mathrm{Tm}^{3+} / \mathrm{Yb}^{3+}$ couple. We can rationalize our results by considering the maximum phonon energies of the four host materials: ${ }^{6,27}$ the more phonons required for phonon-assisted cross-relaxation, the lower the rate ${ }^{28}$. Our work highlights the possibility of tuning the energy-transfer pathways in lanthanide-based phosphors with the appropriate choice of host material and thereby achieving photon-conversion efficiencies above $100 \%$.

\section{Results}

To investigate the $\mathrm{Tm}^{3+}$-to- $\mathrm{Yb}^{3+}$ energy-transfer mechanism in $\mathrm{Tm}^{3+} / \mathrm{Yb}^{3+}$-codoped $\mathrm{YBO}_{3}$, YAG, $\mathrm{Y}_{2} \mathrm{O}_{3}$, and $\mathrm{NaYF}_{4}$, we recorded luminescence spectra (emission and excitation) and luminescence decay curves. As an example, Fig. 1a shows the emission spectrum of microcrystalline $\mathrm{YBO}_{3}$ doped with $0.1 \% \mathrm{Tm}^{3+}$ and $2 \% \mathrm{Yb}^{3+}$ upon excitation in the blue region (at $465 \mathrm{~nm}$; $21,500 \mathrm{~cm}^{-1}$ ). This spectrum shows similar features to those previously measured on $\mathrm{Tm}^{3+} / \mathrm{Yb}^{3+}$-codoped borates and other host materials ${ }^{29-31}$. The emission line centred at $10,000 \mathrm{~cm}^{-1}$ (shaded red) is due to the ${ }^{2} \mathrm{~F}_{5 / 2} \rightarrow{ }^{2} \mathrm{~F}_{7 / 2}$ transition of $\mathrm{Yb}^{3+}$, and that centred at $12,500 \mathrm{~cm}^{-1}$ (shaded green) is due to the energetically overlapping ${ }^{1} \mathrm{G}_{4} \rightarrow{ }^{3} \mathrm{H}_{5}$ and ${ }^{3} \mathrm{H}_{4} \rightarrow{ }^{3} \mathrm{H}_{6}$ transitions of $\mathrm{Tm}^{3+}$. The appearance of $\mathrm{Yb}^{3+}$-based emission following excitation of the $\mathrm{Tm}^{3+}{ }^{1} \mathrm{G}_{4}$ level (see Fig. $1 \mathrm{~b}$ for an excitation spectrum) evidences the occurrence of energy transfer from $\mathrm{Tm}^{3+}$ to $\mathrm{Yb}^{3+}$.

Many previous studies on $\mathrm{Tm}^{3+} / \mathrm{Yb}^{3+}$-codoped materials have concluded that $\mathrm{Tm}^{3+}$-to- $\mathrm{Yb}^{3+}$ energy transfer follows

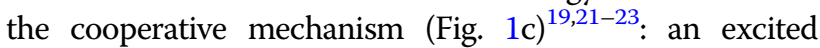
$\mathrm{Tm}^{3+}$ dopant in the ${ }^{1} \mathrm{G}_{4}$ level transfers its energy in a single step to two nearby $\mathrm{Yb}^{3+}$ dopants. This process brings the $\mathrm{Tm}^{3+}$ donor back to its ${ }^{3} \mathrm{H}_{6}$ ground state and excites both $\mathrm{Yb}^{3+}$ acceptor ions to their ${ }^{2} \mathrm{~F}_{5 / 2}$ excited state. Subsequently, both $\mathrm{Yb}^{3+}$ ions can emit a photon with an energy of approximately $10,000 \mathrm{~cm}^{-1}$. Effectively, this process cuts a single blue photon into two infrared photons with sufficient energy to be absorbed by crystalline Si (Fig. 1d $)^{10-12}$.

Evidence for the cooperative mechanism has been scarce to absent ${ }^{12}$. The near match between the energy of the $\mathrm{Tm}^{3+}{ }^{1} \mathrm{G}_{4}$ level and double the energy of the $\mathrm{Yb}^{3+}$ ${ }^{2} F_{5 / 2}$ level suggests the possibility of cooperative energy transfer ${ }^{21-23}$, but this alone is not proof. In fact, the observation of strong $\mathrm{Yb}^{3+}$ emission in a sample with an $\mathrm{Yb}^{3+}$ doping concentration as low as a few percent ${ }^{21-23}$ is inconsistent with cooperative energy transfer. Indeed, efficient cooperative energy transfer occurs only if a $\mathrm{Tm}^{3+}$ ion is in nearest-neighbour proximity to two $\mathrm{Yb}^{3+}$ ions in the crystal, which is unlikely unless the $\mathrm{Yb}^{3+}$ doping concentration exceeds $\sim 25 \%{ }^{8}$.

An alternative $\mathrm{Tm}^{3+}$-to- $\mathrm{Yb}^{3+}$ energy-transfer mechanism could be cross-relaxation (Fig. 1e) ${ }^{12,32}: \mathrm{Tm}^{3+}$ in the excited ${ }^{1} \mathrm{G}_{4}$ level transfers part of its energy to a nearby $\mathrm{Yb}^{3+}$ ion. $\mathrm{Tm}^{3+}$ thereby relaxes to the intermediate ${ }^{3} \mathrm{H}_{5}$ level and $\mathrm{Yb}^{3+}$ is excited to the ${ }^{2} \mathrm{~F}_{5 / 2}$ level. Although $\mathrm{Yb}^{3+}$ 

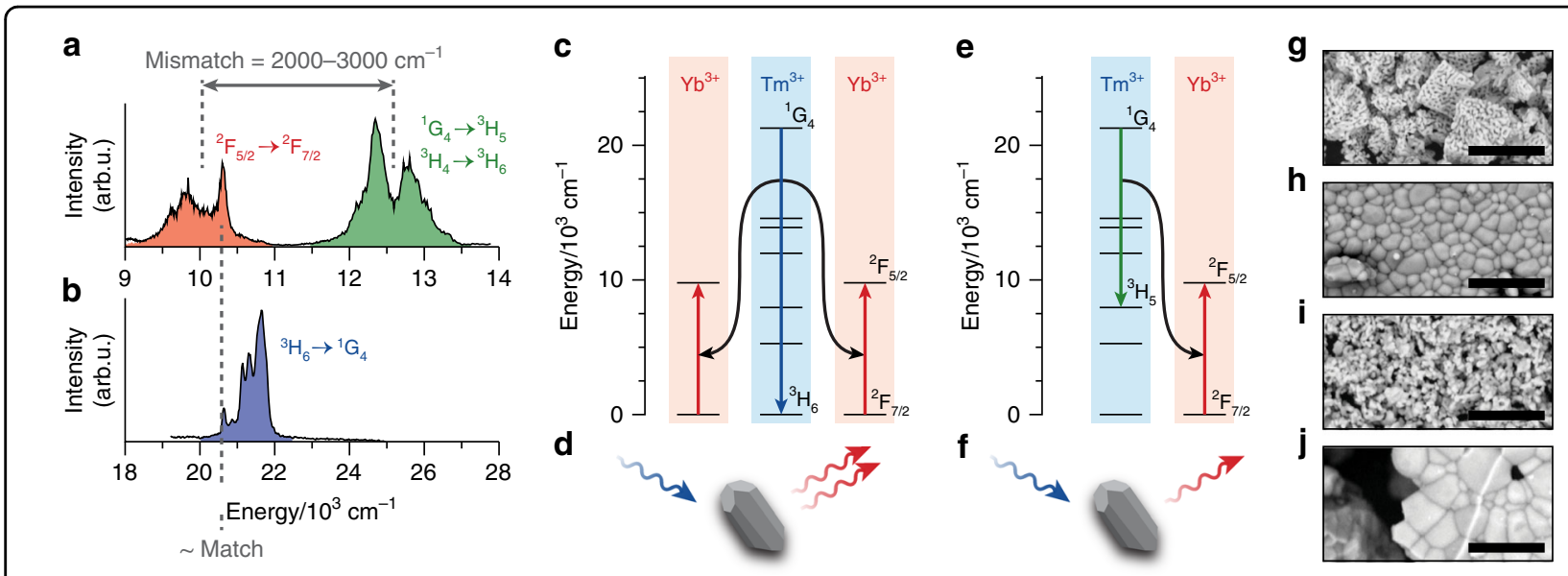

Fig. 1 Basic properties of $\mathrm{Tm}^{3+} / \mathrm{Yb}^{3+}$ codoped phosphors. a Emission spectrum of $\mathrm{YBO}_{3}$ doped with $0.1 \% \mathrm{Tm}^{3+}$ and $2 \% \mathrm{Yb}^{3+}$ upon excitation of the $\mathrm{Tm}^{3+}{ }^{1} \mathrm{G}_{4}$ level at $465 \mathrm{~nm}$. The red-shaded band is due to the ${ }^{2} \mathrm{~F}_{5 / 2} \rightarrow{ }^{2} \mathrm{~F}_{7 / 2}$ emission of $\mathrm{Yb}^{3+}$, and the green-shaded band is due to the overlapping ${ }^{1} \mathrm{G}_{4} \rightarrow{ }^{3} \mathrm{H}_{5}$ and ${ }^{3} \mathrm{H}_{4} \rightarrow{ }^{3} \mathrm{H}_{6}$ emissions of $\mathrm{Tm}^{3+}{ }^{31}$. b Corresponding excitation spectrum, measured by scanning through the $\mathrm{Tm}^{3+}$ ${ }^{3} \mathrm{H}_{6} \rightarrow{ }^{1} \mathrm{G}_{4}$ absorption transition and recording the intensity of the ${ }^{1} \mathrm{G}_{4} \rightarrow{ }^{3} \mathrm{~F}_{4}$ emission at $653 \mathrm{~nm}\left(15,300 \mathrm{~cm}^{-1}\right)$. c Cooperative energy transfer involves the distribution of the excited-state energy in the $\mathrm{Tm}^{3+}{ }^{1} \mathrm{G}_{4}$ level over two nearby $\mathrm{Yb}^{3+}$ ions. $\mathbf{d}$ This can eventually yield two near-infrared photons of $1000 \mathrm{~nm}$ emitted by $\mathrm{Yb}^{3+}$ per blue photon absorption event. e A $\mathrm{Tm}^{3+}$ ion in the ${ }^{1} \mathrm{G}_{4}$ level can alternatively transfer part of its energy to a single nearby $\mathrm{Yb}^{3+}$ ion through phonon-assisted cross-relaxation. $\mathbf{f}$ This produces at most one near-infrared photon of $1000 \mathrm{~nm}$. $\mathbf{g}$-j Scanning electron micrographs of the four host materials in order of decreasing highest phonon energy: $\mathbf{g} \mathrm{YBO}_{3}, \mathbf{h} \mathrm{YAG}_{3} \mathbf{i} \mathrm{Y}_{2} \mathrm{O}_{3}$, and $\mathbf{j} \mathrm{NaYF_{4 }}$. The scale bars represent $5 \mu \mathrm{m}$

can subsequently emit a photon that can be absorbed by crystalline $\mathrm{Si}$, the energy of the ${ }^{3} \mathrm{H}_{5}$ level $\left(8500 \mathrm{~cm}^{-1}\right)$ is lower than the bandgap of $\mathrm{Si}$. Hence, $\mathrm{Tm}^{3+}-\mathrm{to}^{-} \mathrm{Yb}^{3+}$ cross-relaxation yields at most one useful photon (Fig. 1f) for Si-based photovoltaics.

$\mathrm{Tm}^{3+}$-to- $\mathrm{Yb}^{3+}$ cross-relaxation may seem unlikely, as the energy mismatch between the $\mathrm{Tm}^{3+}{ }^{1} \mathrm{G}_{4} \rightarrow{ }^{3} \mathrm{H}_{5}$ and $\mathrm{Yb}^{3+}{ }^{2} \mathrm{~F}_{7 / 2} \rightarrow{ }^{2} \mathrm{~F}_{5 / 2}$ transitions is as large as $2000-3000 \mathrm{~cm}^{-1}$ (compare Fig. 1a, b) ${ }^{31}$. This energy mismatch could, however, be bridged by multiphonon emission. As multiphonon processes generally become less efficient as the number of phonons involved increa$\mathrm{ses}^{28}$, one may expect a strong effect of the host material on the occurrence of cross-relaxation. To test and exploit this, we investigated the $\mathrm{Tm}^{3+}$-to- $\mathrm{Yb}^{3+}$ energy transfer in a series of host materials with different phonon energies (Fig. 1g-j). Specifically, we prepared microcrystalline $\mathrm{Tm}^{3+} / \mathrm{Yb}^{3+}$-codoped $\mathrm{YBO}_{3}$ (Fig. 1a, b, g; highest phonon energy of $\left.1050 \mathrm{~cm}^{-1}\right)^{33,34}$, YAG (Fig. $\left.1 \mathrm{~h} ; 860 \mathrm{~cm}^{-1}\right)^{35,36}$, $\mathrm{Y}_{2} \mathrm{O}_{3}$ (Fig. 1i; $\left.600 \mathrm{~cm}^{-1}\right)^{37}$, and $\mathrm{NaYF}_{4}$ (Fig. 1j; $\left.370 \mathrm{~cm}^{-1}\right)^{38}$. In these materials, $\mathrm{Tm}^{3+}$-to- $\mathrm{Yb}^{3+}$ crossrelaxation would be a two-phonon-, three-phonon-, fourphonon-, or six-phonon-assisted process, respectively, considering a mismatch of $\sim 2000 \mathrm{~cm}^{-1}$ between the closest crystal-field components of the transitions involved (see Fig. 1a). A series of samples was prepared for each material with systematically varied $\mathrm{Yb}^{3+}$ concentration. The $\mathrm{Tm}^{3+}$ concentrations were chosen to be low enough to minimize $\mathrm{Tm}^{3+}$-to- $\mathrm{Tm}^{3+}$ cross-relaxation ${ }^{39,40}$ but sufficiently high to obtain a sufficient luminescence signal. X-ray diffraction (XRD) analysis (Supplementary Fig. S1, Supplementary Information) confirmed the synthesis of phase-pure samples for all $\mathrm{Yb}^{3+}$ concentrations. The different crystallite sizes (Fig. 1g-j) in the range of $100 \mathrm{~nm}-1 \mu \mathrm{m}$ have negligible influence on the energytransfer interactions, because these occur mostly at distances of $1 \mathrm{~nm}$ and shorter. We have previously found only minor influences of the crystal size even for particles as small as $2 \mathrm{~nm}$ in radius ${ }^{41}$.

The emission spectra of the four $\mathrm{Tm}^{3+} / \mathrm{Yb}^{3+}$-codoped materials are qualitatively similar (Fig. 2a-d). All four materials show an emission feature centred at $12,500 \mathrm{~cm}^{-1}$ that is strongest at $0 \% \mathrm{Yb}^{3+}$ (dark red) and becomes weaker for higher $\mathrm{Yb}^{3+}$ concentrations (from red to blue/purple). This emission originates from the ${ }^{1} \mathrm{G}_{4} \rightarrow{ }^{3} \mathrm{H}_{5}$ and ${ }^{3} \mathrm{H}_{4} \rightarrow{ }^{3} \mathrm{H}_{6}$ transitions of $\mathrm{Tm}^{3+}$ (compare Fig. 1a). The decreasing intensity is further confirmation of $\mathrm{Tm}^{3+}$-to- $\mathrm{Yb}^{3+}$ energy transfer, which becomes more efficient at higher $\mathrm{Yb}^{3+}$ concentrations. Indeed, the emission feature at $\sim 10,000 \mathrm{~cm}^{-1}$, due to the $\mathrm{Yb}^{3+}{ }^{2} \mathrm{~F}_{5 / 2} \rightarrow{ }^{2} \mathrm{~F}_{7 / 2}$ transition (compare Fig. 1a), increases in intensity with increasing $\mathrm{Yb}^{3+}$ concentration in all materials. However, for the highest $\mathrm{Yb}^{3+}$ concentrations (>10\% in Fig. $2 \mathrm{a}-\mathrm{c}$ or $>25 \%$ in Fig. 2d), the emission at $10,000 \mathrm{~cm}^{-1}$ is partly quenched. We ascribe this to concentration quenching. The line shapes of $\mathrm{Tm}^{3+}{ }^{1} \mathrm{G}_{4} \rightarrow{ }^{3} \mathrm{H}_{5}, \quad \mathrm{Tm}^{3+}{ }^{3} \mathrm{H}_{4} \rightarrow{ }^{3} \mathrm{H}_{6}$, and $\mathrm{Yb}^{3+}{ }^{2} \mathrm{~F}_{5 / 2} \rightarrow{ }^{2} \mathrm{~F}_{7 / 2}$ are different for the four materials but consistent with previous literature reports ${ }^{42,43}$. The 

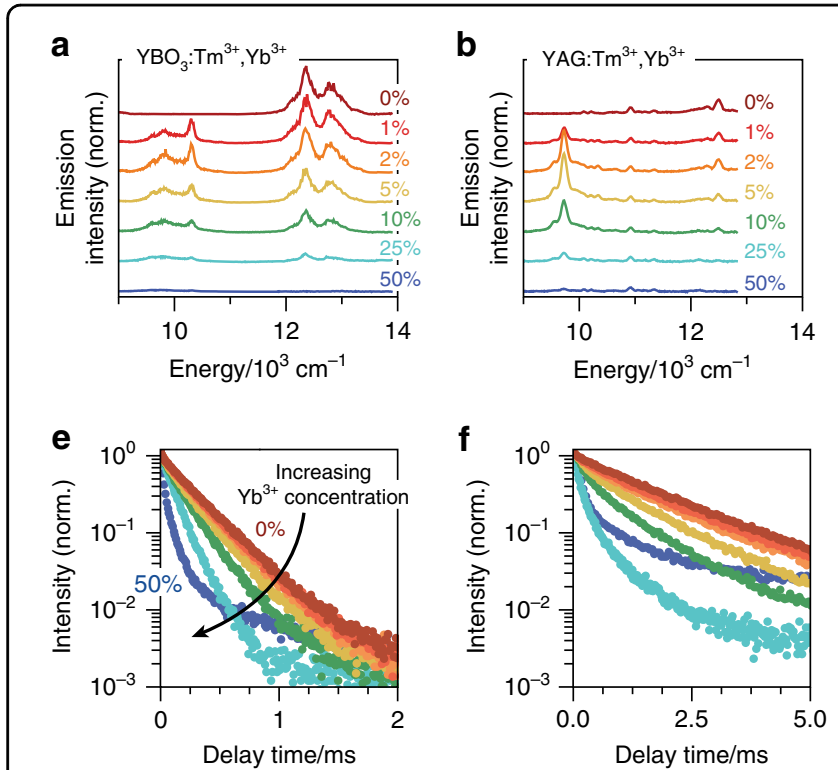
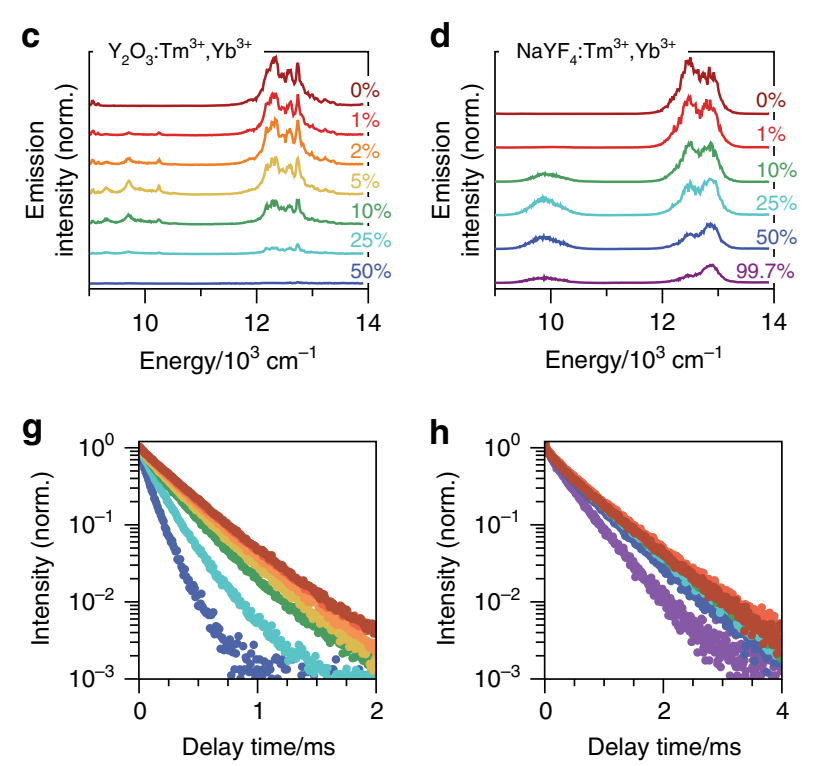

Fig. 2 Emission spectra and decay dynamics as a function of $\mathrm{Yb}^{\mathbf{3}+}$ concentration. a Emission spectra of $\mathrm{YBO}_{3}$ doped with $0.1 \% \mathrm{Tm}^{3+}$ and increasing $\mathrm{Yb}^{3+}$ concentration as indicated in the plot, excited in the $\mathrm{Tm}^{3+1} \mathrm{G}_{4}$ level. The emission bands at $10,000 \mathrm{~cm}^{-1}$ and $12,000 \mathrm{~cm}^{-1}$ are due to radiative relaxation of the $\mathrm{Yb}^{3+}{ }^{2} \mathrm{~F}_{5 / 2}$ and $\mathrm{Tm}^{3+}{ }^{1} \mathrm{G}_{4}$ levels (with overlap of ${ }^{3} \mathrm{H}_{4} \rightarrow{ }^{3} \mathrm{H}_{6}$ emission), respectively. b Same as in $\mathbf{a}$, but for YAG. The Tm ${ }^{3+}$ concentration is $0.03 \%$ in these samples. $\mathbf{c}$ Same as in $\mathbf{a}$, but for $\mathrm{Y}_{2} \mathrm{O}_{3}$. The $\mathrm{Tm}^{3+}$ concentration is $0.1 \%$ in these samples. $\mathbf{d}$ Same as in $\mathbf{a}$, but for NaYF ${ }_{4}$. The $\mathrm{Tm}^{3+}$ concentration is $0.3 \%$ in these samples. e- $\mathbf{h}$ Photoluminescence decay curves of the ${ }^{1} \mathrm{G}_{4}$ level measured for the ${ }^{1} \mathrm{G}_{4} \rightarrow{ }^{3} \mathrm{~F}_{4}$ emission $(\sim 650 \mathrm{~nm})$ from the same samples studied in $\mathbf{a}-\mathbf{d}$, using the same colour coding. These results show accelerated decay due to energy transfer at increasing $\mathrm{Yb}^{3+}$ concentration. All experiments were performed by exciting $\mathrm{Tm}^{3+}$ to the ${ }^{1} \mathrm{G}_{4}$ level $(\sim 65 \mathrm{~nm})$

differences are due to the different crystal fields experienced by the optically active lanthanides, which split the spin-orbit levels and affect the transition energies and rates differently in each material.

Identifying the mechanism and quantifying the efficiency of $\mathrm{Tm}^{3+}$-to- $\mathrm{Yb}^{3+}$ energy transfer requires measurement of the emission decay dynamics. As expected, we observe that for all four materials, the excited-state lifetime of the $\mathrm{Tm}^{3+}$ ${ }^{1} \mathrm{G}_{4}$ level decreases with increasing $\mathrm{Yb}^{3+}$ concentration (Fig. 2e-h). This confirms energy transfer from the $\mathrm{Tm}^{3+}{ }^{1} \mathrm{G}_{4}$ level to $\mathrm{Yb}^{3+}$. At higher $\mathrm{Yb}^{3+}$ concentrations, $\mathrm{Tm}^{3+}$ ions have (on average) more and closer $\mathrm{Yb}^{3+}$ neighbours, so the energy-transfer rates are higher. At the highest $\mathrm{Yb}^{3+}$ concentrations (50\% in Fig. 2e, f), the $\mathrm{Tm}^{3+}$ emission intensity is strongly quenched, so the signal-to-background ratio in the photoluminescence decay measurement is poor. Comparing the measurements on the different materials, we note that the decay dynamics depend less strongly on the $\mathrm{Yb}^{3+}$ concentration in $\mathrm{NaYF}_{4}$ (Fig. 2h) than in the other materials (Fig. 2e-g). This is our first indication that the $\mathrm{Tm}^{3+}$-to- $\mathrm{Yb}^{3+}$ energy transfer depends on the maximum phonon energy of the host material.

As a first analysis of the energy-transfer mechanisms in the four materials, we use the data of Fig. $2 \mathrm{e}-\mathrm{h}$ and evaluate the average lifetime of the $\mathrm{Tm}^{3+}{ }^{1} \mathrm{G}_{4}$ level, $\langle\tau\rangle=\sum_{i} I_{i} t_{i} / \sum_{i} I_{i}$, where $I_{i}$ is the emission intensity at delay time $t_{i}$ and the summation runs over all data points $i$ constituting the photoluminescence decay curve as a function of $\mathrm{Yb}^{3+}$ concentration. The inverse of the average lifetime (Fig. 3a-d) is approximately equal to the average decay rate of the ${ }^{1} \mathrm{G}_{4}$ level,

$$
\langle\tau\rangle^{-1} \approx k_{0}+\left\langle k_{\mathrm{ET}}\right\rangle
$$

where the first term $k_{0}$ is due to relaxation processes not involving $\mathrm{Yb}^{3+}$, e.g., radiative decay or multiphonon relaxation, and the second term $k_{\mathrm{ET}}$ is due to energy transfer to $\mathrm{Yb}^{3+}$. The $k_{\mathrm{ET}}$ of a $\mathrm{Tm}^{3+}$ ion depends on the number of $\mathrm{Yb}^{3+}$ neighbours and hence on the $\mathrm{Yb}^{3+}$ doping concentration $x$ in the crystal. Indeed, for all four host materials, $\tau^{-1}$ shows a constant offset $k_{0}$ and a second term $k_{\mathrm{ET}}$ that increases with $\mathrm{Yb}^{3+}$ concentration. The outlying data points for the highest $\mathrm{Yb}^{3+}$ concentration in $\mathrm{YBO}_{3}$ and YAG (Fig. 3a, b) are due to the low signal-to-background ratio for these measurements, which makes accurate calculation of $\tau$ difficult.

The results of Fig. 3a-d indicate a qualitative difference in the energy-transfer mechanism between the higherphonon-energy hosts- $\mathrm{YBO}_{3}$, YAG, and $\mathrm{Y}_{2} \mathrm{O}_{3}$-and the lowest-phonon-energy host $\mathrm{NaYF}_{4}$. In the higherphonon-energy hosts, $k_{\mathrm{ET}}$ scales linearly with $\mathrm{Yb}^{3+}$ concentration $x$ (dotted lines in Fig. $3 \mathrm{a}-\mathrm{c}$ ). This indicates the occurrence of cross-relaxation (Fig. 1e, f), which is a firstorder process that scales linearly with the acceptor 
concentration. In contrast, $\mathrm{NaYF}_{4}$ shows a quadratic trend (dashed line in Fig. 3d). More precisely, fitting the power of the $k_{\mathrm{ET}} \propto x^{p}$ relationship (not shown) yields $p=1.8$, close to a value of 2 . This is consistent with cooperative

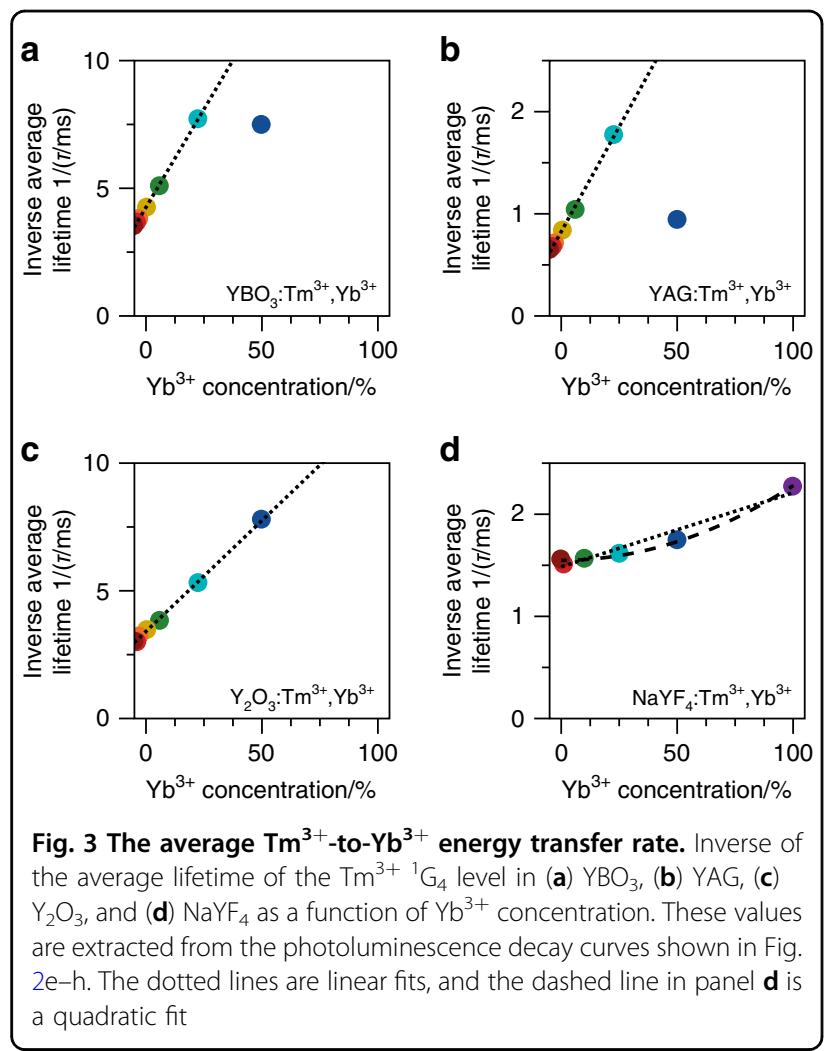

energy transfer (Fig. 1c, d), which is a second-order process.

For further confirmation and quantification of the energy-transfer process, we turn to Monte Carlo modelling of the ${ }^{1} \mathrm{G}_{4}$ decay dynamics ${ }^{8,44}$. As the energy-transfer rates scale strongly with the distance between the donor and acceptor and $\mathrm{Tm}^{3+}$ and $\mathrm{Yb}^{3+}$ dopants randomly substitute $\mathrm{Y}^{3+}$ cation sites in the host crystal, we expect that different $\mathrm{Tm}^{3+}$ ions in the crystal exhibit different energy-transfer rates. For a particular donor-acceptor pair, the energy-transfer rate for cross-relaxation via dipole-dipole coupling is

$$
k_{\mathrm{ET}}=\frac{C_{\mathrm{xr}}}{r^{6}}
$$

where $r$ is the donor-acceptor separation and $C_{\mathrm{xr}}$ is a prefactor describing the overall strength of crossrelaxation. Cooperative energy transfer requires one donor and two acceptors and scales as

$$
k_{\mathrm{ET}}=\frac{C_{\text {coop }}}{r_{1}{ }^{6} r_{2}{ }^{6}}
$$

where $r_{1}$ is the distance from the donor to acceptor $1, r_{2}$ is the distance from the donor to acceptor 2 , and $C_{\text {coop }}$ is the strength of cooperative energy transfer ${ }^{8}$. To model the energy transfer dynamics in a $\mathrm{Tm}^{3+} / \mathrm{Yb}^{3+}$-codoped sample, we Monte Carlo simulate dopant configurations and calculate from these the distribution of energytransfer rates following Eqs. (2) and (3). More details of the model can be found in the Experimental section.

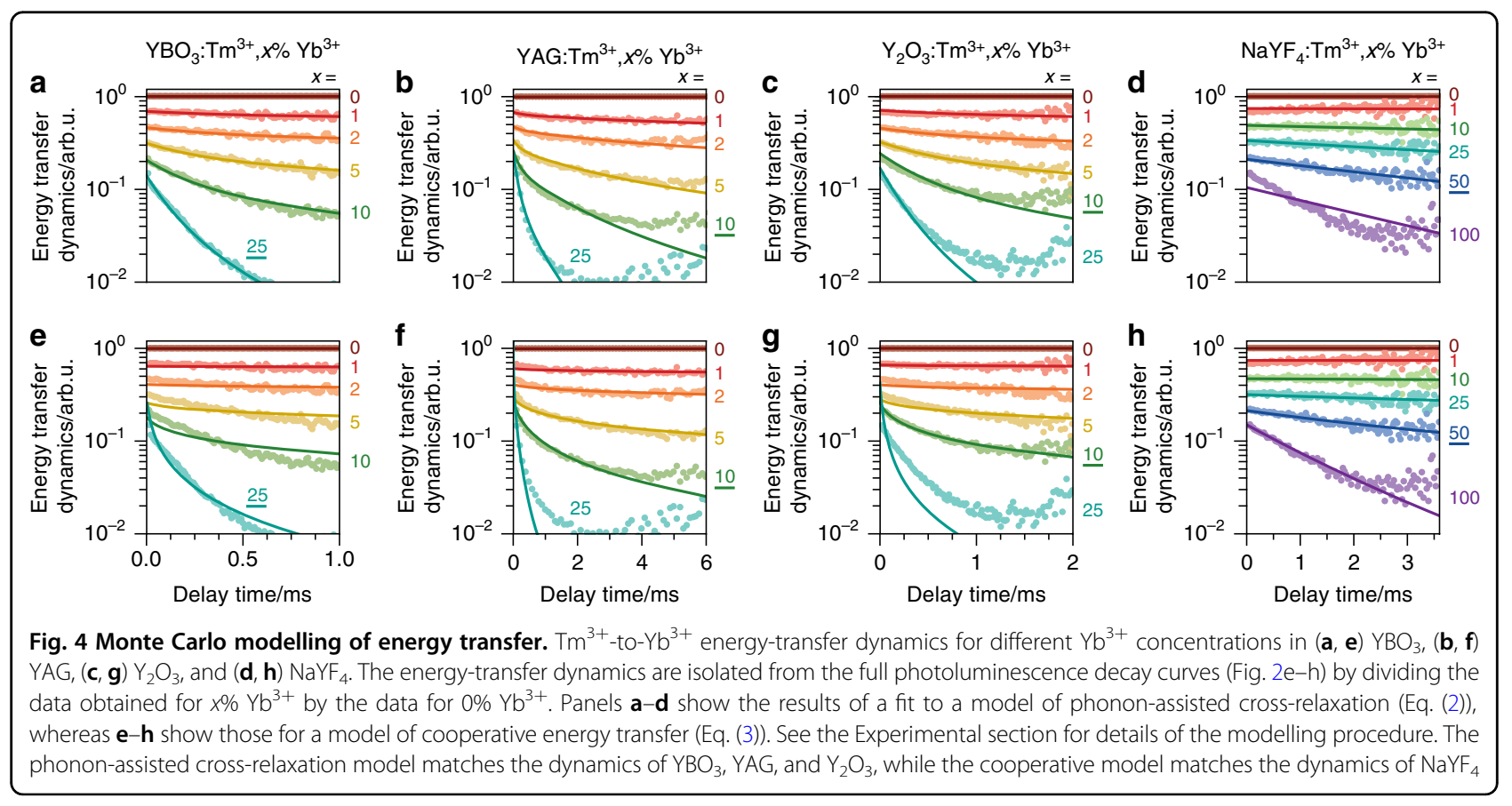


Figure 4 shows the $\mathrm{Tm}^{3+}$-to- $\mathrm{Yb}^{3+}$ energy-transfer dynamics in our samples. We isolate the $\mathrm{Tm}^{3+}-$ to- $\mathrm{Yb}^{3+}$ energy-transfer dynamics from the total photoluminescence decay curves (Fig. $2 \mathrm{e}-\mathrm{h}$ ) by following the procedure introduced in Ref. ${ }^{41}$ : we divide each decay curve of a sample with $x \% \mathrm{Yb}^{3+}$ by the decay curve of the corresponding sample with $0 \% \mathrm{Yb}^{3+}$. We thus use the sample with $0 \% \mathrm{Yb}^{3+}$ as a reference to remove the dynamics due to radiative decay of $\mathrm{Tm}^{3+}$ and $\mathrm{Tm}^{3+}$-to$\mathrm{Tm}^{3+}$ from our data. Solid lines are fits to the Monte Carlo model for cross-relaxation (Eq. 2; Fig. 4a-d) or to the model for cooperative energy transfer (Eq. (3) and Fig. $4 \mathrm{e}-\mathrm{h})$. For each host material, we first determine the optimal values of $C_{\mathrm{xr}}$ and $C_{\text {coop }}$ for one $\mathrm{Yb}^{3+}$ concentration, as underlined in Fig. 4. Then, keeping the values found fixed, we plot the calculated decay curves for the other concentrations. The cross-relaxation model well matches the data for $\mathrm{YBO}_{3}$, YAG, and $\mathrm{Y}_{2} \mathrm{O}_{3}$ (Fig. 4a-c), while the cooperative model predicts too slow a decay at low $\mathrm{Yb}^{3+}$ concentrations and too rapid a decay at high $\mathrm{Yb}^{3+}$ concentrations (Fig. $4 \mathrm{e}-\mathrm{g}$ ). In contrast, for $\mathrm{NaYF}_{4}$, the cooperative model works well (Fig. 4h), whereas the cross-relaxation model shows deviations from the experimental data (Fig. 4d).

The quantitative analysis of Fig. 4 confirms that the energy-transfer mechanisms are different between the higher-phonon-energy hosts $\left(\mathrm{YBO}_{3}, \mathrm{YAG}\right.$, and $\left.\mathrm{Y}_{2} \mathrm{O}_{3}\right)$ and $\mathrm{NaYF}_{4}$. Cross-relaxation occurs in the higher-phononenergy hosts, with rates comparable to radiative decay at $\mathrm{Yb}^{3+}$ concentrations as low as a few percent. In contrast, in $\mathrm{NaYF}_{4}$, the $\mathrm{Tm}^{3+}$-to- $\mathrm{Yb}^{3+}$ energy transfer is weak until high $\mathrm{Yb}^{3+}$ concentrations of $>25 \%$, and cooperative energy transfer dominates over radiative decay only at higher concentrations. Hence, we must conclude that $\mathrm{NaYF}_{4}$ allows for cooperative $\mathrm{Tm}^{3+}$-to- $\mathrm{Yb}^{3+}$ energy transfer not because the rate of this process is particularly high but rather because cross-relaxation is strongly suppressed.

\section{Discussion}

We can determine how weak the cross-relaxation is in $\mathrm{NaYF}_{4}$ compared to the other hosts by analysing the measurements at low $\mathrm{Yb}^{3+}$ concentrations $(\leq 25 \%)$ using the cross-relaxation model. This yields values for the $\mathrm{Tm}^{3}$ ${ }^{+}$-to- $\mathrm{Yb}^{3+}$ cross-relaxation strength in $\mathrm{NaYF}_{4}$ of $C_{\mathrm{xr}}=$ $(7 \pm 6) \times 10^{1} \AA^{6} \mathrm{~ms}^{-1}$. Cross-relaxation in $\mathrm{NaYF}_{4}$ is thus two orders of magnitude slower than that in the higherphonon-energy hosts (Fig. 5a). This is consistent with the large energy mismatch between the ${ }^{1} \mathrm{G}_{4} \rightarrow{ }^{3} \mathrm{H}_{5}$ and ${ }^{2} \mathrm{~F}_{7 /}$ ${ }_{2} \rightarrow{ }^{2} \mathrm{~F}_{5 / 2}$ transitions involved in cross-relaxation (compare Fig. 1a, b). Our experiments show that the $2000-3000 \mathrm{~cm}^{-1}$ mismatch can be bridged by a two-, three-, or four-phonon process in $\mathrm{YBO}_{3}$, YAG, or $\mathrm{Y}_{2} \mathrm{O}_{3}$, respectively. In contrast, the six-phonon-assisted cross-
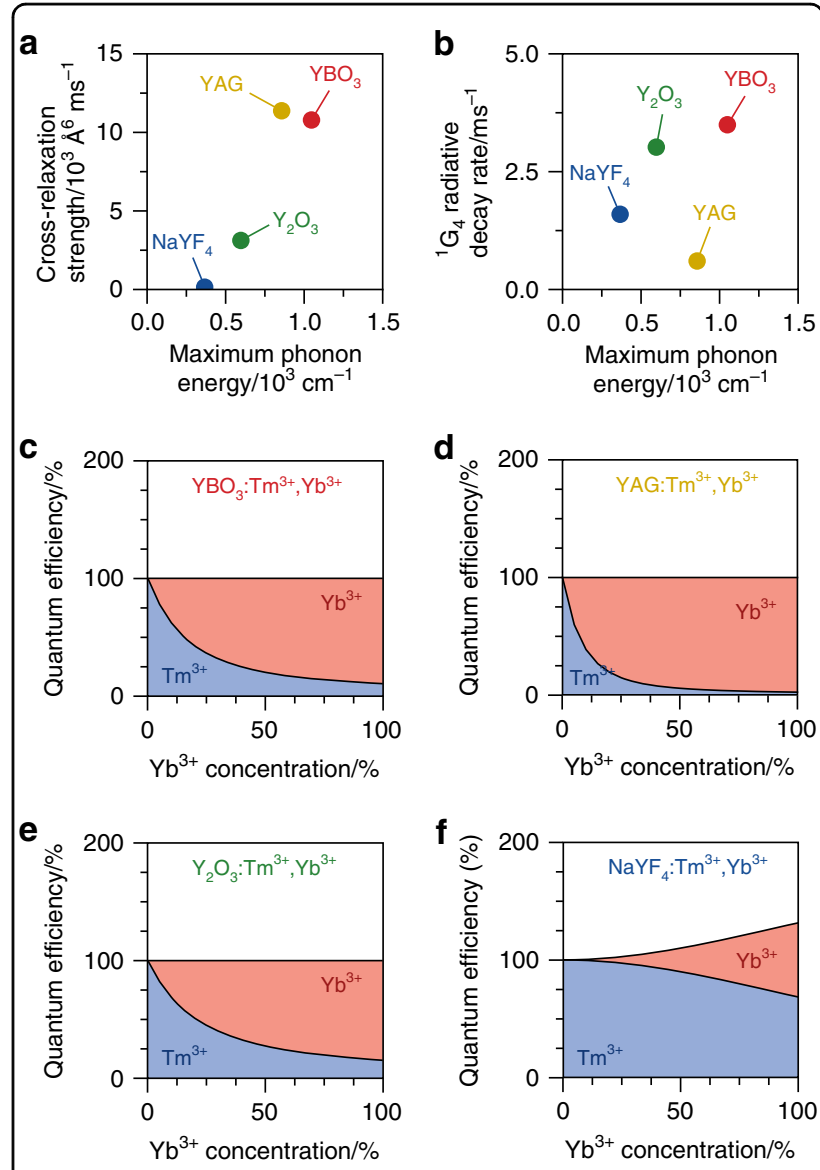

Fig. 5 Comparing the photon-cutting potential of different host materials. a Fitted $\mathrm{Tm}^{3+}$-to-Y $\mathrm{Yb}^{3+}$ cross-relaxation strength $C_{\mathrm{xr}}$ (see Eq. (2)) for the different host materials, plotted as a function of the maximum phonon energy of the host. $\mathbf{b}$ Corresponding intrinsic decay rates of the ${ }^{1} G_{4}$ level. c Calculated maximum quantum efficiency of $\mathrm{YBO}_{3}: \mathrm{Tm}^{3+}, \mathrm{Yb}^{3+}$ as a function of $\mathrm{Yb}^{3+}$ concentration based on our phonon-assisted cross-relaxation model. We count only emission that can be absorbed by crystalline $\mathrm{Si}$, i.e., visible emission from the $\mathrm{Tm}^{3+}{ }^{1} \mathrm{G}_{4}$ level (blue-shaded area) and near-infrared emission from $\mathrm{Yb}^{3+}$ (red-shaded area), and assume zero nonradiative decay from the $\mathrm{Yb}^{3+}{ }^{3} \mathrm{~F}_{5 / 2}$ level. d Same, but for $\mathrm{YAG}: \mathrm{Tm}^{3+}, \mathrm{Yb}^{3+}$. e Same, but for $\mathrm{Y}_{2} \mathrm{O}_{3}: \mathrm{Tm}^{3+}, \mathrm{Yb}^{3+}$. f Same, but for $\mathrm{NaYF}_{4}: \mathrm{Tm}^{3+}, \mathrm{Yb}^{3+}$ and using our model for cooperative energy transfer. Of the four materials studied, only NaYF $4: \mathrm{Tm}^{3+}, \mathrm{Yb}^{3+}$ is a photon-cutting phosphor that can produce two near-infrared photons (useful for crystalline Si) from a single blue photon absorption event

relaxation in $\mathrm{NaYF}_{4}$ is too slow to compete with other decay pathways from the $\mathrm{Tm}^{3+}{ }^{1} \mathrm{G}_{4}$ level. Closer inspection of Fig. 5a reveals that four-phonon-assisted crossrelaxation in $\mathrm{Y}_{2} \mathrm{O}_{3}$ is already slower by a factor of 3 than the corresponding lower-order processes in $\mathrm{YBO}_{3}$ and YAG. Qualitatively, such a strong dependence of the cross-relaxation rates on the number of phonons involved is expected from the exponential energy-gap law for nonradiative relaxation ${ }^{28}$. Quantitatively, however, the relation between the number of phonons involved and the 
cross-relaxation strength $\left(C_{\mathrm{xr}}\right)$ is not straightforward, as $C_{\mathrm{xr}}$ depends on various other factors such as the transition dipole moments of the electronic and vibrational transitions involved ${ }^{28,45}$. In general, lanthanide $\mathrm{f}-\mathrm{f}$ transition dipole moments are different for different host materials, as they are strongly dependent on the crystalfield symmetry and covalency of the host material ${ }^{45}$. This explains why the intrinsic ${ }^{1} \mathrm{G}_{4}$ decay rates $k_{0}$ are different for the different host materials (Fig. 5b) and why $C_{\mathrm{xr}}$ does not monotonically increase with phonon energy (Fig. 5a). Future work may reveal that temperature further affects the delicate competition between phonon-assisted crossrelaxation and cooperative energy transfer.

The energy-transfer mechanism, the corresponding energy-transfer strength $\left(C_{\mathrm{xr}}\right.$ or $C_{\text {coop }}$ Eqs. (2) and (3)), and the decay rate $k_{0}$ of the ${ }^{1} \mathrm{G}_{4}$ level at $0 \% \mathrm{Yb}^{3+}$ (Fig. 5b) determine the maximum quantum efficiency of visible-tonear-infrared photon-conversion achievable with a particular host material. In our definition of quantum efficiency, we include only the emission of photons that can be absorbed by crystalline Si. Creating two of these photons from a single $\mathrm{Tm}^{3+}$ ion in the ${ }^{1} \mathrm{G}_{4}$ level requires cooperative energy transfer rather than cross-relaxation. To calculate the maximum quantum efficiency, we first construct the theoretical normalised photoluminescence decay curve of the ${ }^{1} G_{4}$ level for each host material for any arbitrary $\mathrm{Yb}^{3+}$ concentration:

$$
I(t)=\mathrm{e}^{-k_{0} t} T(t)
$$

where $T(t)$ is the multiexponential decay function due to energy transfer (see the 'Methods' section for details). The theoretical quantum efficiency is then given by

$$
\eta=\eta_{\mathrm{Tm}}+\eta_{\mathrm{Yb}}
$$

Herein,

$$
\eta_{\mathrm{Tm}}=k_{0} \int_{0}^{\infty} I(t) \mathrm{d} t
$$

is the efficiency of $\mathrm{Tm}^{3+}{ }^{1} \mathrm{G}_{4}$ emission, and

$$
\eta_{\mathrm{Yb}}=Q\left(1-\eta_{\mathrm{Tm}}\right)
$$

is the efficiency of $\mathrm{Yb}^{3+}$ emission. The factor $Q$ depends on the dominant energy-transfer mechanism in the host material. Its value is $Q=1$ for the cross-relaxation process in $\mathrm{YBO}_{3}, \mathrm{YAG}$, and $\mathrm{Y}_{2} \mathrm{O}_{3}$ or $Q=2$ for cooperative energy transfer in $\mathrm{NaYF}_{4}$.

In Fig. $5 c-f$, we plot the maximum quantum efficiency for the different host materials as a function of $\mathrm{Yb}^{3+}$ concentration, calculated with our Monte Carlo model. We neglect intrinsic losses in $\mathrm{Tm}^{3+}$ due to nonradiative decay or infrared emissions as well as concentration quenching effects of the $\mathrm{Yb}^{3+}$ emission (see Fig. 2a-d). The calculations of Fig. $5 \mathrm{c}-\mathrm{f}$ thus show the highest possible quantum efficiency that could be achieved if the materials are optimized to suppress any loss channel. As expected, the $\mathrm{Yb}^{3+}$ emission rapidly increases with increasing $\mathrm{Yb}^{3+}$ concentration in the higher-phononenergy hosts (Fig. $5 \mathrm{c}-\mathrm{e}$ ), but the overall quantum efficiency never exceeds unity. In contrast, in $\mathrm{NaYF}_{4}$, the $\mathrm{Yb}^{3+}$ emission increases more slowly but pushes the overall quantum efficiency up to $132 \%$ in $\mathrm{NaYbF}_{4}: \mathrm{Tm}^{3+}$.

Our findings highlight the possibility of qualitatively altering the energy-conversion pathways in lanthanidedoped crystals by choosing a host material with the appropriate phonon spectrum. This allows us to change the blue-to-near-infrared conversion by the $\mathrm{Tm}^{3+} / \mathrm{Yb}^{3+}$ couple from a simple downshifting process in the higherphonon-energy host materials into a photon-cutting process in the lower-phonon-energy host $\mathrm{NaYF}_{4}$. Only photon cutting in the $\mathrm{NaYF}_{4}$ host holds promise for enhancement of the current output of crystalline Si solar cells because it can convert blue photons into nearinfrared photons of $\sim 1000 \mathrm{~nm}$ with a quantum efficiency exceeding unity. Similar qualitative differences between host materials may be expected in terms of the (often very complicated) pathways of photon upconversion ${ }^{46}$. While previous studies have claimed achievement of high photon-cutting efficiencies with the $\mathrm{Tm}^{3+} / \mathrm{Yb}^{3+}$ couple in a wide variety of host materials, our findings show that photon cutting is only possible in host lattices with phonon energies not exceeding $\sim 400 \mathrm{~cm}^{-1}$.

\section{Materials and methods \\ Chemicals and materials}

All chemicals were used without further purification. $\mathrm{Y}_{2} \mathrm{O}_{3}$ (99.999\%) was purchased from Alfa Aesar; $\mathrm{Tm}_{2} \mathrm{O}_{3}$ (99.999\%) from Heraeus; $\mathrm{Yb}_{2} \mathrm{O}_{3}$ (99.99\%), $\mathrm{Y}_{2} \mathrm{O}_{3}$ (99.99\%), $\mathrm{Al}\left(\mathrm{NO}_{3}\right)_{3} \cdot 9 \mathrm{H}_{2} \mathrm{O}(\geq 98 \%)$, urea (BioReagent), and nitric acid $\left(\mathrm{HNO}_{3}\right.$; puriss. p.a., $\left.\geq 65 \%\right)$ from Sigma-Aldrich; and boric acid $\left(\mathrm{H}_{3} \mathrm{BO}_{3} ; \geq 99.5 \%\right)$ from Merck.

\section{Synthesis of $\beta-\mathrm{NaYF}_{4}: \mathrm{Tm}^{3+}, \mathrm{Yb}^{3+}$ microcrystalline phosphors}

$\beta-\mathrm{NaYF}_{4}: 0.3 \% \mathrm{Tm}^{3+}, x \% \mathrm{Yb}^{3+}$ powder samples were synthesized following the approach developed by Krämer et al. .

\section{Combustion synthesis of $\mathrm{Y}_{2} \mathrm{O}_{3}-, \mathrm{YAG}_{-}$, and $\mathrm{YBO}_{3}$-based polycrystalline phosphors}

A urea-nitrate solution combustion process was used for the synthesis of a series of polycrystalline powder phosphors of $\mathrm{Y}_{2} \mathrm{O}_{3}$, YAG, and $\mathrm{YBO}_{3}$ codoped with $\mathrm{Tm}^{3+}$ and $\mathrm{Yb}^{3+}$. $\mathrm{Y}_{2} \mathrm{O}_{3}, \mathrm{Tm}_{2} \mathrm{O}_{3}$, and $\mathrm{Yb}_{2} \mathrm{O}_{3}$ were used as lanthanide (Ln) sources, $\mathrm{Al}\left(\mathrm{NO}_{3}\right)_{3} .9 \mathrm{H}_{2} \mathrm{O}$ as the $\mathrm{Al}$ source for YAG, $\mathrm{H}_{3} \mathrm{BO}_{3}$ 
as the $\mathrm{B}$ source for $\mathrm{YBO}_{3}$, and urea as the organic fuel for the combustion reaction. Stoichiometric amounts of $\mathrm{Y}_{2} \mathrm{O}_{3}$, $\mathrm{Tm}_{2} \mathrm{O}_{3}$, and $\mathrm{Yb}_{2} \mathrm{O}_{3}$ were dissolved in nitric acid to obtain aqueous solutions of mixed $\operatorname{Ln}\left(\mathrm{NO}_{3}\right)_{3}$. For the synthesis of $\mathrm{Y}_{2} \mathrm{O}_{3}: \mathrm{Tm}^{3+}, \mathrm{Yb}^{3+}$, solid urea (molar ratio urea/ $\mathrm{Ln}=2: 1$ ) was added to the $\operatorname{Ln}\left(\mathrm{NO}_{3}\right)_{3}$ solution. For YAG: $\mathrm{Tm}^{3+}, \mathrm{Yb}^{3+}$, an $\mathrm{Al}\left(\mathrm{NO}_{3}\right)_{3}$ solution (molar ratio $\mathrm{Al} / \mathrm{Ln}=5: 3$ ) and urea (molar ratio urea/ $\mathrm{Ln}=5: 1$ ) were added to the $\mathrm{Ln}\left(\mathrm{NO}_{3}\right)_{3}$ solution. For $\mathrm{YBO}_{3}: \mathrm{Tm}^{3+}, \mathrm{Yb}^{3+}$, solid urea (molar ratio urea/ $\mathrm{Ln}=3: 1)$ and $\mathrm{H}_{3} \mathrm{BO}_{3}(5 \%$ molar excess) were added to the $\mathrm{Ln}\left(\mathrm{NO}_{3}\right)_{3}$ solution. After vigorous stirring for $20 \mathrm{~min}$ at approximately $70^{\circ} \mathrm{C}$, the resulting homogeneous precursor solution was placed in a preheated furnace at $500^{\circ} \mathrm{C}$ in air to initiate the combustion reaction. Amorphous solid precursors formed from the solutions within a few minutes. Finally, annealing in ambient atmosphere at $1000^{\circ} \mathrm{C}$ for $4 \mathrm{~h}$, $1500^{\circ} \mathrm{C}$ for $10 \mathrm{~h}$, and $900^{\circ} \mathrm{C}$ for $4 \mathrm{~h}$ produced crystalline $\mathrm{Tm}^{3+} / \mathrm{Yb}^{3+}$-codoped $\mathrm{Y}_{2} \mathrm{O}_{3}$, YAG, and $\mathrm{YBO}_{3}$, respectively.

\section{Characterization}

Phase identification of all the prepared products was performed on a Philips PW1700 X-ray powder diffractometer using $\mathrm{Cu} \mathrm{K}-\alpha(\lambda=1.5418 \AA)$ radiation. XRD patterns were collected over a $2 \theta$ range from $10^{\circ}$ to $80^{\circ}$ at an interval of $0.02^{\circ}$. The morphology of the samples was checked using high-resolution scanning electron microscopy (Phenom ProX Desktop SEM, $10 \mathrm{keV}$ ) and a thin layer of sample powder on conducting carbon tape. Steadystate emission and excitation spectra were recorded using an Edinburgh Instruments FLS920 spectrophotometer equipped with different excitation sources, including a $450 \mathrm{~W}$ xenon lamp and an optical parametric oscillator laser (OPO; Opolette HE 355II; $20 \mathrm{~Hz}$; pulse width $\sim 7 \mathrm{~ns}$ ), TMS300 monochromators, a thermoelectrically cooled R928 photomultiplier tube (PMT) for visible wavelengths, and a liquid-nitrogen-cooled R5509-72 PMT for nearinfrared wavelengths. Photoluminescence decay curves were measured using multichannel scaling on the Edinburgh Instruments FLS920 spectrophotometer under pulsed OPO laser excitation.

\section{Modelling the energy-transfer dynamics}

We used the Monte Carlo procedure to model the dynamics of the cross-relaxation and cooperative energy transfer described in detail in Ref. ${ }^{44}$. Briefly, for each host material, we randomly generated several thousand different environments of an excited $\mathrm{Tm}^{3+}$ ion, i.e., a number of nearest $\mathrm{Yb}^{3+}$ neighbours, next-nearest neighbours, etc., taking into account the overall $\mathrm{Yb}^{3+}$ doping concentration. $\mathrm{NaYF}_{4}$ and $\mathrm{Y}_{2} \mathrm{O}_{3}$ have two possible crystal sites for the central $\mathrm{Tm}^{3+}$ ion, which were weighted by the relative occurrence. We made the simplification that the energy-transfer strengths $C_{\mathrm{xr}}$ and $C_{\text {coop }}$ are the same for all sites in the crystal structures. Next, for each environment $i$, we calculated the total energy-transfer rate $k_{\mathrm{ET}, i}$ by summing over all (pairs of) acceptors (see Eqs. (2) and (3)) and obtained an expression $T(t)=A \sum_{i} e^{-k_{\mathrm{ET}, i} t}$ for the multiexponential energy-transfer dynamics. We determined the best value for $C_{\mathrm{xr}}$ (Eq. (2)) or $C_{\text {coop }}$ (Eq. (3)) by fitting our model to the data for one of the $\mathrm{Yb}^{3}$ ${ }^{+}$concentrations, indicated in Fig. 4 by the underlined value for $x$. Finally, we fitted our model to the data for all other $\mathrm{Yb}^{3+}$ concentrations, only optimizing the amplitudes $A$ while keeping $C_{\mathrm{xr}}$ or $C_{\text {coop }}$ fixed.

\begin{abstract}
Acknowledgements
This work was supported by the National Science Foundation of China (U1601205, 51472088, and 51125005) and by The Netherlands Center for Multiscale Catalytic Energy Conversion (MCEC), an NWO Gravitation programme funded by the Ministry of Education, Culture, and Science of the government of The Netherlands. F.T.R. acknowledges financial support from The Netherlands Organisation for Scientific Research NWO (VENI grant number 722.017.002). We thank T. van Swieten for critical reading of the manuscript.
\end{abstract}

\section{Conflict of interest}

The authors declare that they have no conflict of interest.

Supplementary information is available for this paper at https://doi.org/ 10.1038/s41377-020-00346-z.

Received: 29 January 2020 Revised: 28 May 2020 Accepted: 8 June 2020 Published online: 19 June 2020

\section{References}

1. George, N. C., Denault, K. A. \& Seshadri, R. Phosphors for solid-state white lighting. Annu. Rev. Mater. Res. 43, 481-501 (2013).

2. Tanner, P. A. et al. Misconceptions in electronic energy transfer: bridging the gap between chemistry and physics. Chem. Soc. Rev. 47, 5234-5265 (2018).

3. Brites, C. D. S., Balabhadra, S. \& Carlos, L. D. Lanthanide-based thermometers: at the cutting-edge of luminescence thermometry. Adv. Opt. Mater. 7, 1801239 (2019).

4. Krämer, K. W. et al. Hexagonal sodium yttrium fluoride based green and blue emitting upconversion phosphors. Chem. Mater. 16, 1244-1251 (2004).

5. Zhou, B. et al. Controlling upconversion nanocrystals for emerging applications. Nat. Nanotechnol. 10, 924-936 (2015).

6. Gao, G. J. et al. Up-conversion fluorescent labels for plastic recycling: a review. Adv. Sustain. Syst. 1, 1600033 (2017).

7. Wegh, R. T. et al. Visible quantum cutting in $\mathrm{LiGdF}_{4}$ : $\mathrm{Eu}^{3+}$ through downconversion. Science 283, 663-666 (1999).

8. Vergeer, $\mathrm{P}$. et al. Quantum cutting by cooperative energy transfer in $\mathrm{Yb}_{x} \mathrm{Y}_{1-\mathrm{x}} \mathrm{PO}_{4}: \mathrm{Tb}^{3+}$. Phys. Rev. B 71, 014119 (2005).

9. Smet, P. F. Parmentier, A. B. \& Poelman, D. Selecting conversion phosphors for white light-emitting diodes. J. Electrochem. Soc. 158, R37-R54 (2011).

10. Richards, B. S. Luminescent layers for enhanced silicon solar cell performance: down-conversion. Sol. Energy Mater. Sol. Cells 90, 1189-1207 (2006).

11. van der Ende, B. M., Aarts, L. \& Meijerink, A. Near-infrared quantum cutting for photovoltaics. Adv. Mater. 21, 3073-3077 (2009).

12. Huang, X. Y. et al. Enhancing solar cell efficiency: the search for luminescent materials as spectral converters. Chem. Soc. Rev. 42, 173-201 (2013).

13. Shockley, W. \& Queisser, H. J. Detailed balance limit of efficiency of $p-n$ junction solar cells. J. Appl. Phys. 32, 510-519 (1961).

14. Trupke, T., Green, M. A. \& Würfel, P. Improving solar cell efficiencies by downconversion of high-energy photons. J. Appl. Phys. 92, 1668-1674 (2002).

15. Zhang, Q. Y. et al. Concentration-dependent near-infrared quantum cutting in $\mathrm{GdBO}_{3}: \mathrm{Tb}^{3+}, \mathrm{Yb}^{3+}$ nanophosphors. Appl. Phys. Lett. 90, 061914 (2007).

16. Veda, J. \& Tanabe, S. Visible to near infrared conversion in $\mathrm{Ce}^{3+}-\mathrm{Yb}^{3+} \mathrm{CO}-$ doped YAG ceramics. J. Appl. Phys. 106, 043101 (2009).

17. $\mathrm{Yu}, \mathrm{D}$. C. et al. Insights into the energy transfer mechanism in $\mathrm{Ce}^{3+}-\mathrm{Yb}^{3+}$ codoped YAG phosphors. Phys. Rev. B 90, 165126 (2014). 
18. Zhou, L. et al. Spectral properties and energy transfer between $\mathrm{Ce}^{3+}$ and $\mathrm{Yb}^{3+}$ in the $\mathrm{Ca}_{3} \mathrm{Sc}_{2} \mathrm{Si}_{3} \mathrm{O}_{12}$ host: is it an electron transfer mechanism? J. Phys. Chem. A 120, 5539-5548 (2016).

19. Xie, L. C., Wang, Y. H. \& Zhang, H. J. Near-infrared quantum cutting in $\mathrm{YPO}_{4}: \mathrm{Yb}^{3+}, \mathrm{Tm}^{3+}$ via cooperative energy transfer. Appl. Phys. Lett. 94, 061905 (2009).

20. Zheng, W. et al. Visible-to-infrared quantum cutting by phonon-assisted energy transfer in $\mathrm{YPO}_{4}: \mathrm{Tm}^{3+}, \mathrm{Yb}^{3+}$ phosphors. Phys. Chem. Chem. Phys. 14 6974-6980 (2012).

21. Jiang, G. C. et al. Broadband downconversion in $\mathrm{YO}_{4}: \mathrm{Tm}^{3+}, \mathrm{Yb}^{3+}$ phosphors. J. Rare Earths 31, 27-31 (2013).

22. $\mathrm{Fu}$, L. et al. Efficient near-infrared quantum cutting in $\mathrm{Tm}^{3+} / \mathrm{Mb}^{3+}$ codoped LiYF4 single crystals for solar photovoltaic. Chin. J. Chem. Phys. 28, 73-78 (2015).

23. Lisiecki, R. et al. Contribution of energy transfer processes to excitation and relaxation of $\mathrm{Yb}^{3+}$ ions in $\mathrm{Gd}_{3}(\mathrm{Al}, \mathrm{Ga})_{5} \mathrm{O}_{12}: \mathrm{RE}^{3+}, \mathrm{Yb}^{3+}\left(\mathrm{RE}^{3+}=\mathrm{Tm}^{3+}, \mathrm{Er}^{3+}\right.$, $\mathrm{Ho}^{3+}, \mathrm{Pr}^{3+}$ ). J. Lumin. 211, 54-61 (2019).

24. van Wijngaarden, J. T. et al. Energy transfer mechanism for downconversion in the $\left(\mathrm{Pr}^{3+}, \mathrm{Yb}^{3+}\right)$ couple. Phys. Rev. B 81, 155112 (2010).

25. $\mathrm{Xu}, \mathrm{Y}$. S. et al. Efficient near-infrared down-conversion in $\mathrm{Pr}^{3+}-\mathrm{Yb}^{3+}$ codoped glasses and glass ceramics containing $\mathrm{LaF}_{3}$ nanocrystals. J. Phys. Chem. C. 115, 13056-13062 (2011)

26. De Jong, M., Meijerink, A. \& Rabouw, F. T. Non-poissonian photon statistics from macroscopic photon cutting materials. Nat. Commun. 8, 15537 (2017).

27. Auzel, F. On the maximum splitting of the $\left({ }^{2} \mathrm{~F}_{7 / 2}\right)$ ground state in $\mathrm{Yb}^{3+}$-doped solid state laser materials. J. Lumin. 93, 129-135 (2001).

28. van Dijk, J. M. F. \& Schuurmans, M. F. H. On the nonradiative and radiative decay rates and a modified exponential energy gap law for $4 \mathrm{f}-4 \mathrm{f}$ transitions in rare-earth ions. J. Chem. Phys. 78, 5317-5323 (1983).

29. Guyot, $Y$. et al. Luminescence properties of $\mathrm{Y}_{2} \mathrm{O}_{3}$ single crystals doped with $\mathrm{Pr}^{3+}$ or $\mathrm{Tm}^{3+}$ and codoped with $\mathrm{Yb}^{3+}, \mathrm{Tb}^{3+}$ or $\mathrm{Ho}^{3+}$ ions. Optical Mater. 5 127-136 (1996).

30. Fei, B. J. et al. Spectroscopic properties and laser performance of Tm: YAG ceramics. J. Lumin. 142, 189-195 (2013).

31. Ju, M. et al. Deciphering the microstructure and energy-level splitting of $\mathrm{Tm}^{3+}$-doped yttrium aluminum garnet. Inorg. Chem. 58, 1058-1066 (2019).
32. Yadav, R. et al. Observation of multi-mode: upconversion, downshifting and quantum-cutting emission in $\mathrm{Tm}^{3+} \mathrm{Nb}^{3+}$ co-doped $\mathrm{Y}_{2} \mathrm{O}_{3}$ phosphor. Chem. Phys. Lett. 599, 122-126 (2014).

33. Denning, J. H. \& Boss, S. D. The vibrational spectra and structures of some rare-earth borates. Spectrochim. Acta A Mol. Spectrosc. 28, 1775-1785 (1972).

34. Boyer, D., Bertrand, G. \& Mahiou, R. A spectroscopic study of the vaterite form $\mathrm{YBO}_{3}$ : $\mathrm{Eu}^{3+}$ processed by sol-gel technique. J. Lumin. 104, 229-237 (2003).

35. Koningstein, J. A. \& Mortensen, O. S. Laser-excited phonon raman spectrum of garnets. J. Mol. Spectrosc. 27, 343-350 (1968).

36. Slack, G. A. et al. Optical absorption of $\mathrm{Y}_{3} \mathrm{Al}_{5} \mathrm{O}_{12}$ from 10- to $55000-\mathrm{cm}^{-1}$ wave numbers. Phys. Rev. J. Arch. 177, 1308-1314 (1969).

37. Repelin, Y. et al. Vibrational spectroscopy of the C-form of yttrium sesquioxide J. Solid State Chem. 118, 163-169 (1995).

38. Suyver, J. F. et al. Upconversion spectroscopy and properties of $\mathrm{NaYF}_{4}$ doped with $\mathrm{Er}^{3+}, \mathrm{Tm}^{3+}$ and/or $\mathrm{Yb}^{3+}$. J. Lumin. 117, 1-12 (2006).

39. Chen, $X$. B. et al. Multiphoton near-infrared quantum cutting luminescence phenomena of $\mathrm{Tm}^{3+}$ ion in $\left(\mathrm{Y}_{1-x} \mathrm{Tm}_{x}\right)_{3} \mathrm{Al}_{5} \mathrm{O}_{12}$ powder phosphor. Opt. Express 21, A829-A840 (2013)

40. $\mathrm{Yu}, \mathrm{D}$. C. et al. Multi-photon quantum cutting in $\mathrm{Gd}_{2} \mathrm{O}_{2} \mathrm{~S}: \mathrm{Tm}^{3+}$ to enhance the photo-response of solar cells. Light. Sci. Appl. 4, e344 (2015).

41. Rabouw, F. T. et al. Photonic effects on the Förster resonance energy transfer efficiency. Nat. Commun. 5, 3610 (2014).

42. Thomas, J. T. et al. Optical spectroscopy of $\mathrm{Tm}^{3+}$ : YAG transparent ceramics. J. Phys. D Appl. Phys. 46, 375301 (2013).

43. Dodson, C. M. et al. Magnetic dipole emission of $\mathrm{Dy}^{3+}: \mathrm{Y}_{2} \mathrm{O}_{3}$ and $\mathrm{Tm}^{3+}: \mathrm{Y}_{2} \mathrm{O}_{3}$ at near-infrared wavelengths. Optical Mater. Express 4, 2441-2450 (2014).

44. Rabouw, F. T. \& Meijerink, A. Modeling the cooperative energy transfer dynamics of quantum cutting for solar cells. J. Phys. Chem. C. 119, 2364-2370 (2015).

45. Henderson, B. \& Imbusch, G. F. Optical Spectroscopy of Inorganic Solids. (Oxford Univ. Press, Oxford, 2006).

46. Teitelboim, A. et al. Energy transfer networks within upconverting nanoparticles are complex systems with collective, robust, and history-dependent dynamics. J. Phys. Chem. C 123, 2678-2689 (2019). 